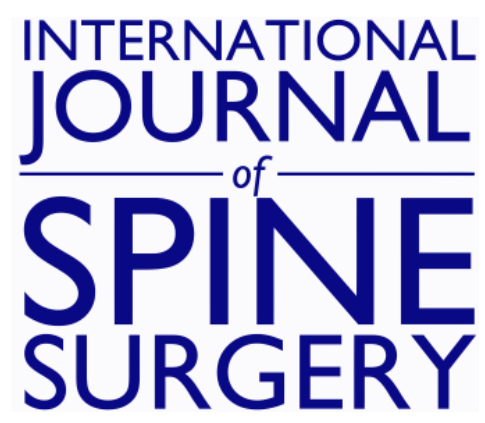

\title{
Prognostic Value of Michigan State University (MSU) Classification for Lumbar Disc Herniation: Is It Suitable for Surgical Selection?
}

Manuela d'Ercole, Gualtiero Innocenzi, Francesco Ricciardi and Simona Bistazzoni

Int J Spine Surg 2021, 15 (3) 466-470

doi: https://doi.org/10.14444/8068

http://ijssurgery.com/content/15/3/466

This information is current as of April 25, 2023.

Email Alerts Receive free email-alerts when new articles cite this article. Sign up at:

http://ijssurgery.com/alerts

The International Journal of Spine Surgery

2397 Waterbury Circle, Suite 1,

Aurora, IL 60504, Phone: +1-630-375-1432 


\title{
Prognostic Value of Michigan State University (MSU) Classification for Lumbar Disc Herniation: Is It Suitable for Surgical Selection?
}

\author{
MANUELA D'ERCOLE, MD, PHD, ${ }^{1}$ GUALTIERO INNOCENZI, MD, ${ }^{2}$ FRANCESCO RICCIARDI, MD, ${ }^{2}$ \\ SIMONA BISTAZZONI, MD, PHD \\ ${ }^{I}$ Department of Neurosurgery, Fondazione Policlinico Universitario "A. Gemelli," Università Cattolica del Sacro Cuore, Roma, Italy, ${ }^{2}$ Department of \\ Neurosurgery, IRCCS Neuromed, Pozzilli (IS), Italy, ${ }^{3}$ Department of Neurosurgery, Sant'Anna Hospital, Como, Italy
}

\begin{abstract}
Background: Lumbar disc herniation (LDH) is the most common cause of radiculopathy; patients with severe pain refractory to conservative management or neurological deficits are candidates to surgical procedures. Michigan State University (MSU) classification is a radiological codification considering both the size of the LDH and its medial to lateral location on the axial plane. The purpose of this retrospective study is to identify which kind of LDH, according to the MSU scheme, is more likely to cause a motor deficit.

Methods: We performed a retrospective analysis on data obtained from 114 patients treated with 117 lumbar microdiscectomies after failure of non-operative care. All patients underwent neurological and functional evaluation before and after surgery according to the following: Oswestry Disability Index, visual analog scale, and Japanese Orthopaedic Association back pain evaluation questionnaire. Magnetic resonance imaging proved that disc herniation was classified according to the MSU scheme and was correlated with motor disturbances expressed according to Medical Research Council grade.

Results: Statistical analysis showed a significant correlation between the lateral location of disc herniation (preforaminal and extraforaminal LDH, respectively MSU B and MSU C) and the grade of muscle weakness, given that the LDH in these locations poorly responded to medical therapy and was at higher risk for motor deficit onset; no significant correlation with the size was observed.

Conclusions: Beyond standardization of radiologic description, MSU classification proved to be useful in definition of prognosis and possibly in selection of surgical candidates. However, these data should be confirmed by prospective studies on a larger sample of patients, also including those under way for conservative treatment.
\end{abstract}

Lumbar Spine

Keywords: lumbar disc herniation, radiculopathy, MSU, ODI, JOA, VAS

\section{INTRODUCTION}

Lumbar disc herniation (LDH), defined as displacement of the central nucleus beyond the margins of the annulus fibrosus, is considered the most common cause of radiculopathy, resulting from compression of 1 or more spinal nerve roots and manifesting as radiating leg pain and paresthesias (a sensation of tingling, burning and numbness) with or without neurological deficits. ${ }^{1}$

The vast majority of patients with sciatica do not require surgical intervention due to the favorable natural history. ${ }^{2}$ Patients with severe symptoms, refractory to conservative management in 6-8 weeks, progressive or severe neurological deficits, or cauda equina syndrome are surgical candidates.
Neurological deficit following LDH is a rare event, with a reported incidence of less than $2 \%{ }^{3}$

The present investigation is a retrospective study exclusively involving a population of patients who underwent surgical treatment due to having persistent pain despite conservative treatments and/or neurological deficit onset. Our purpose was to try to identify which kind of LDH, classified according to the Michigan State University (MSU) scheme, ${ }^{4}$ was more likely to develop a neurological deficit and thus select patients for early surgical treatment.

\section{MATERIALS AND METHODS}

We retrospectively examined a surgical series of 388 patients treated with lumbar radicular decompression in a 1-year period (January 2018-Decem- 
Table 1. Distribution of LDH according to level.

\begin{tabular}{lc}
\hline Level & LDH (n) \\
\hline L5-S1 & 52 \\
L4-L5 & 52 \\
L3-L4 & 9 \\
L2-L3 & 4 \\
\hline
\end{tabular}

Abbreviation: LDH, lumbar disc herniation.

ber 2018) by the same neurosurgical team (IRCCS Neuromed, Pozzilli, Italy). Among these, 114 patients (49 women, 65 men; mean age $=46$, range 20-78 years) undergoing 117 lumbar microdiscectomies for $\mathrm{LDH}$ were considered in the present study; 3 patients were treated for double $\mathrm{LDH}$. Distribution of LDH according to level is shown in Table 1. Inclusion criteria, based on clinical and radiological data, were radicular pain related to 1 or $2 \mathrm{LDH}$ in patients who had failed 6-8 weeks of conservative care, including physical and medical treatment, and/or the onset of neurological deficits, regardless of conservative attempts; an insignificant to mild degree of stenosis, referred to as a grade A according to the Schizas classification. ${ }^{5}$ Patients suffering from multilevel disc herniation $(\geq 3)$ and other possible causes of radicular impingement, such as significant stenosis (Schizas B, C, D) and spondylolisthesis, were excluded from the study. All patients were submitted to neurological examination at the time of admission that assessed straight leg raising, presence of sensory disturbance, bladder dysfunction, and muscle weakness according to Medical Research Council (MRC) grade. All patients had magnetic resonance imaging (MRI)proven $\mathrm{LDH}$, corresponding to the side and area of radiculopathy. MRI images were reviewed by the senior author (G.I.): Each LDH was measured in axial view in its relative size compared with bone landmarks, both in anterior-posterior and in medial-lateral extension, and classified according to the Michigan State University (MSU) classification (Figure 1). Statistical correlation between muscle weakness and radiological aspects of $\mathrm{LDH}$ were assessed by 2-way analysis of variance, whereas a Mann-Whitney rank sum test and Bonferroni correction were used for statistical significance. Significance was defined as $P \leq .05$. Sensory disturbances, although evaluated, were not included in the statistical analysis. Pain in its individual aspects and its impact on daily life were also evaluated before and after surgery according to the Oswestry Disability Index (ODI), visual analog scale (VAS), and Japanese Orthopaedic Association

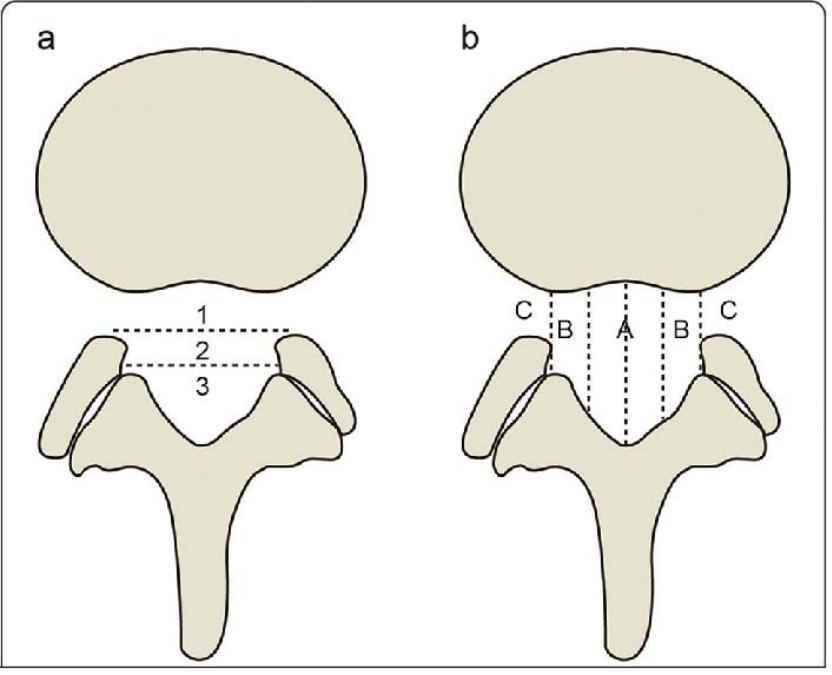

Figure 1. MSU classification results from combination of size and location of LDH: (a) grading LDH for size with growing impact on nerve compression from grades 1-3; (b) medial to lateral LDH location from zone A to zone C. Abbreviations: LDH, lumbar disc herniation; MSU, Michigan State University.

back pain evaluation questionnaire (JOA), although no statistical analysis was performed on these data due to their subjective character.

\section{RESULTS}

The straight leg raising was positive in approximately $87.7 \%$ (100 points; Lasegue $<30^{\circ}: 27.2 \%$ [31 points]; Lasegue, $30^{\circ}-70^{\circ}: 60.5 \%$ [69 points]), sensory disturbances were present in $66.7 \%$ (76 points), muscle weakness was seen in 57.9\% (MRC grade 1: $0.9 \%$ [1 point], MRC grade 2: $0.9 \%$ [1 point], MRC grade 3: 16.7\% [19 points], MRC grade $4: 39.5 \%$ [ 45 points]) and bladder dysfunction was impaired in approximately $4.4 \%$ of the participants ( 5 points). Patients affected by motor deficits $(57.9 \%)$ were immediately scheduled for surgery, regardless of evolution of pain.

The LDH distribution according to MSU classification is shown in Table 2; these data have been correlated to degree of muscle weakness, which is presented in Table 3. Statistical analysis of collected data showed a significant difference $(P=.022)$ between the grade of muscle weakness and the lateral position of disc herniation, considering both

Table 2. Distribution of LDH according to MSU classification.

\begin{tabular}{lrrrr}
\hline Grade & A & B & C & AB \\
\hline 1 & $\ldots$ & 1 & $\ldots$ & $\ldots$ \\
2 & 3 & 28 & 8 & 11 \\
3 & 19 & 24 & $\ldots$ & 23 \\
\hline
\end{tabular}

Abbreviations: LDH, lumbar disc herniation; MSU, Michigan State University. 
Table 3. Correlation between size and location of LDH according to MSU classification and motor disturbances according to MRC scale.

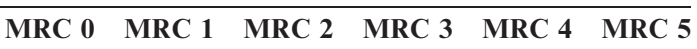

\begin{tabular}{lllllll}
\hline MSU A1 & $\ldots$ & $\ldots$ & $\ldots$ & $\ldots$ & $\ldots$ & $\ldots$ \\
MSU A2 & $\ldots$ & $\ldots$ & 1 & $\ldots$ & $\ldots$ & 2 \\
MSU A3 & $\ldots$ & $\ldots$ & $\ldots$ & 1 & 4 & 14 \\
MSU B1 & $\ldots$ & $\ldots$ & $\ldots$ & $\ldots$ & 1 & $\ldots$ \\
MSU B2 & $\ldots$ & $\ldots$ & $\ldots$ & 4 & 12 & 12 \\
MSU B3 & $\ldots$ & 1 & $\ldots$ & 1 & 11 & 11 \\
MSU C1 & $\ldots$ & $\ldots$ & $\ldots$ & $\ldots$ & $\ldots$ & $\ldots$ \\
MSU C2 & $\ldots$ & $\ldots$ & $\ldots$ & 4 & 3 & 1 \\
MSU C3 & $\ldots$ & $\ldots$ & $\ldots$ & $\ldots$ & $\ldots$ & $\ldots$ \\
MSU AB1 & $\ldots$ & $\ldots$ & $\ldots$ & $\ldots$ & $\ldots$ & $\ldots$ \\
MSU AB2 & $\ldots$ & $\ldots$ & $\ldots$ & 3 & 3 & 5 \\
MSU AB3 & $\ldots$ & $\ldots$ & $\ldots$ & 6 & 11 & 6
\end{tabular}

Abbreviations: LDH, lumbar disc herniation; MRC, Medical Research Council; MSU, Michigan State University.

preforaminal (MSU B) and extraforaminal (MSU C) locations. No statistically significant $(P=.327)$ correlation between the size of disc herniation and the grade of muscle weakness was noticed. We found that the difference in the median values (Mann-Whitney rank sum test) between the JOA value and size of LDH was greater than would be expected by chance, with a statistically significant difference $(P \leq .001)$. The distribution of patients in preoperative ODI score was $1.7 \%$ (2 points) in the minimal disability group (ODI score, $0 \%-20 \%$ ); $32.5 \%$ (37 points) in the moderate disability group (ODI score, $21 \%-40 \%$ ); 35.1\% (40 points) in the severe disability group (ODI score, $41 \%-60 \%$ ); $21.1 \%$ (24 points) in the disabled group (ODI score, $61 \%-80 \%$ ); and $9.6 \%$ (11 points) in the bedbound group (ODI score, $81 \%-100 \%$ ). The distribution of patients in the preoperative VAS scale was $84.2 \%$ (96 points) with a score $>5$ and $15.8 \%$ (18 points) with a score $\leq 5$. The patients' mean preoperative JOA score was 6.1 (range, 3-14).

\section{DISCUSSION}

The natural course of LDH is generally favorable, and up to $80 \%$ of patients respond to conservative therapy with complete pain relief and neurological recovery in an average of 4-6 weeks. The remaining $20 \%$ of patients have a strong indication for surgical intervention. ${ }^{6}$ Several magnetic resonance (MR) studies have shown a possible regress in $\mathrm{LDH}$ size, with a decrease in neural impingement in a substantial number of patients, usually accompanied by a full recovery. ${ }^{7}$ Several hypotheses about the mechanism of $\mathrm{LDH}$ disappearance have been proposed, such as retraction by posterior longitudinal ligament tension, dehydration, resorption by macrophage phagocytosis, and immunologic reaction. Disappearance is significantly more frequent in migrating $\mathrm{LDH}$, whereas a small disc protrusion may not show any change: Migrating LDH extended over a ruptured posterior longitudinal ligament is probably exposed to the vascular supply, activating inflammatory response, neovascularization, macrophage phagocytosis, and finally hernial resorption. ${ }^{8}$ On the other hand, a clinical improvement can occur even in the absence of any MRI change; this is probably due to decreased pressure on symptomatic nerve root or subsided inflammation around the nerve root, even in the absence of morphological changes. As reported by Bertilson et al, ${ }^{9}$ a nerve involvement evident at physical examination and pain drawing could be underestimated or not detected by MRI, although promising data have resulted from the application of diffusion tensor imaging in the diagnosis of nerve impairment, surgical selection, and timing as well as in postoperative evaluation and prognosis. ${ }^{10}$ Given that a rare, neurological deficit leading to long-lasting disabilities is the most dreaded complication following $\mathrm{LDH}$, the surgeon is faced with the dilemma of whether to intervene in the presence of clinical worsening or adopt a conservative policy that, in theory, could prolong the period of suffering, leading to greater nerve damage or even resulting in cauda equina syndrome. ${ }^{11,12}$ Animal studies $^{13,14}$ have also supported the concept that increased duration of nerve compression results in a greater degree of axonal loss and demyelination, whereas early decompression was seen to reverse these changes. ${ }^{15}$ According to several studies, the overall rate of complete recovery following surgery is superior to the nonoperative arm, including patients undergoing conservative treatments. Balaji et $\mathrm{al}^{2}$ assessed that in patients with severe motor deficits $(\mathrm{MRC} \leq 3)$ it is not possible to dismiss the role for surgery; they reported a $6.4 \%$ difference in the recovery rate between the collective operative and nonoperative groups. Moreover, Buttermann et $\mathrm{al}^{16}$ showed that all of their patients with severe motor deficit recovered to $\mathrm{MRC} \geq 4$ following surgery, but none of their nonoperative patients recovered. Although MR is frequently used in the diagnostic evaluation of $\mathrm{LDH}$, it is not still clear which of their findings can help to predict the proportion of patients who may need surgery. In any case, MR findings should be correlated to 
clinical findings to select patients for surgery. ${ }^{20}$ Many attempts have been performed to standardize the reporting of size and location of $\mathrm{LDH}$ and to simplify the anatomic description of findings on computed tomography and MRI. Classical LDH nomenclature in the coronal and sagittal planes is defined by the craniocaudal extent in comparison with the pedicle and is described as suprapedicular, pedicular, or infrapedicular. Classification on the axial plane is more pragmatic and useful because it describes the location of the herniation relative to the various exiting and traversing nerves, using the medial edge of the facet articulations and the borders of the pedicles or the neural foramina for anatomic landmarks. The boundaries or zones in the axial plane are defined as the central zone, the subarticular zone, the foraminal zone, the extraforaminal or far lateral zone, and the anterior zone. ${ }^{21}$ The MSU classification appears useful in a more accurate qualification of radiological records to standardize the description ${ }^{7}$; our purpose was to find a clinical correlation to obtain an early identification of patients at high risk of onset of neurological deficits (candidates for early surgery). We have found a significative correlation $(P=.022)$ between the lateral location of LDH (MSU B, MSU C) and the grade of muscle weakness, probably due to strict radicular conflict in the neuroforamen. Moreover, a statistically significant correlation $(P \leq .001)$ was recorded between the JOA value and size of disc herniation. As noted by Motiei-Langroudi et $\mathrm{al}^{20}{ }^{20}$ as the LDH occurred farther from the midline and more proximal to the intervertebral foramen and to nerve roots, there was a higher rate of failure to respond to medical therapy. Larger disc fragments with more pronounced compression of the thecal sac are another predictor of failure to response to conservative management. ${ }^{22} \mathrm{LDH}$ larger than $5.9 \mathrm{~mm}$ in the anteroposterior dimensions, canal compromise greater than $59.4 \%$, and narrower (anteroposterior and lateral) bony canals were significantly associated with neurological deficit. ${ }^{23}$ However, by considering the main limit of our study as the use of the MSU classification in patients selected for surgery, these evidences should be verified by applying them to all patients with herniated discs, even those under way for conservative treatment. Of course, a retrospective study entails some limitations: The true value of this classification can ultimately be established only by a prospective study. Our investigation was strictly focused on correlation between LDH and motor disturbances; numbness and sensitive disturbances, in fact, are frequently reported at the beginning of clinical presentation and strictly related to onset of pain, thus being difficult to prevent. ${ }^{24}$ Moreover, sensitive impairment shows a weaker correlation with ODI score when compared with pain score and motor deficit, thus suggesting a lesser influence on social dysfunction. ${ }^{25}$ Another possible limitation may be the fact that MRI images have been classified by only 1 reader; thus, the study considered neither intra-rater nor interrater variability. The comparison between the classification results of several raters may be useful to assess the generalization capability of the MSU classification for the indicated purposes.

\section{CONCLUSIONS}

MSU classification can provide a standardization of radiological description of $\mathrm{LDH}$, useful in communication among spine surgeons. A laterally located LDH (MSU B, MSU C) could be considered a predictor of the onset of neurological deficit, and a large hernia could be a predictor of failure to respond to medical therapy. Although this could be an intuitive issue, the proposed classification could be a useful prognostic tool in the approach to the patient and perhaps in selection of surgical candidates. However, data drawn from this pilot study should be corroborated by multicenter prospective studies on a larger sample of patients, possibly including those under way for conservative treatment. A more extensive study could lead to a quantitative correlation among MSU classification, pain, disability, and prediction of risk of the onset of neurological deficit in order to reinforce the usefulness of this classification.

\section{REFERENCES}

1. Hahne AJ, Ford JJ, McMeeken JM. Conservative management of lumbar disc herniation with associated radiculopathy: a systematic review. Spine (Phila Pa 1976). 2010;35(11):E488-E504.

2. Balaji VR, Chin KF, Tucker S, Wilson LF, Casey AT. Recovery of severe motor deficit secondary to herniated lumbar disc prolapse: is surgical intervention important? A systematic review. Eur Spine J. 2014;23(9):1968-1977.

3. Gilbson JNA, Waddell G. Surgical intervations for lumbar disc prolapse. Cochrane Database Syst Rev. 2007;(2): CD001350

4. Mysliwiec LW, Cholewicki J, Winkelpleck MD, Eis GP. 
MSU classification for herniation lumbar discs on MRI: toward developing objective criteria for surgical selection. Eur Spine J. 2010;19(7):1087-1093.

5. Schizas C, Theumann N, Burn A, et al. Qualitative grading of severity of lumbar spinal stenosis based on the morphology of the dural sac on magnetic resonance images. Spine (Phila Pa 1976). 2010;35(21):1919-1924.

6. Hofstee DJ, Gijtenbeek JM, Hoogland PH, et al. Westeinde sciatica trial: randomized controlled study of bed rest and physiotherapy for acute sciatica. J Neurosurg. 2002;96(suppl 1):45-49.

7. Erly WK, Munoz D, Beaton R. Can MRI signal characteristics of lumbar disk herniations predict disk regression? J Comput Assist Tomogr. 2006;30(3):486-489.

8. Cunha C, Silva AJ, Pereira P, Vaz R, Gonçalves RM, Barbosa MA. The inflammatory response in the regression of lumbar disc herniation. Arthritis Res Ther. 2018;20(1):251. doi:10.1186/s13075-018-1743-4

9. Bertilson $\mathrm{BC} 1$, Brosjö E, Billing $\mathrm{H}$, Strender LE Assessment of nerve involvement in the lumbar spine: agreement between magnetic resonance imaging, physical examination and pain drawing findings. BMC Musculoskelet Disord. 2010;11:202.

10. Li J, Cui H, Liu Z, et al. Utility of diffusion tensor imaging for guiding the treatment of lumbar disc herniation by percutaneous transforaminal endoscopic discectomy. Sci Rep. 2019;9(1):18753. doi:10.1038/s41598-019-55064-3

11. Benson RT, Tavares SP, Robertson SC, Sharp R, Marshall RW. Conservatively treated massive prolapsed discs: a 7-year follow-up. Ann R Coll Engl. 2010;92(2):147-153.

12. Krishnan V, Rajasekaran S, Aiyer SN, Kanna R, Shetty AP. Clinical and radiological factors related to the presence of motor deficit in lumbar disc prolapse: a prospective analysis of 70 consecutive cases with neurological deficit. Eur Spine J. 2017;26(10):2642-2649.

13. Sarikcioglu L, Yaba A, Tanriover G, Demirtop A, Demir N, Ozkan O. Effect of severe crush injury on axonal regeneration: a functional and ultrastructural study. $J$ Reconstr Microsurg. 2007;23(3):143-149.

14. Pham K, Gupta R. Understanding the mechanisms of entrapment neuropathies. Review article. Neurosurg Focus. 2009;26(2):E7.

15. Jancalek R, Dubovy P. An experimental animal model of spinal root compression syndrome: an analysis of morphological changes of myelinated axons during compression radiculopathy and after decompression. Exp Brain Res. 2007;179(1):111-119.

16. Buttermann GR. Treatment of lumbar disc herniation: epidural steroid injection compared with discectomy. A prospective, randomized study. J Bone Joint Surg Am. 2004;86-A(4):670-679.

17. Iizuka Y, Iizuka N, Tsutsumi S, et al. Foot drop due to lumbar degenerative conditions: mechanism and prognostic factors in herniated nucleus pulposus and lumbar spinal stenosis. J Neurosurg Spine. 2009;10(3):260-264.

18. Eysel P, Rompe JD, Hopf C. Prognostic criteria of discogenic paresis. Eur Spine J. 1994;3(4):214-218.

19. Postacchini F, Giannicola G, Cinotti G. Recovery of motor deficits after microdiscectomy for lumbar disc herniation. J Bone Joint Surg Br. 2002; 84(7):1040-1045.

20. Motiei-Langroudi R, Sadeghian H, Seddighi AS. Clinical and magnetic resonance imaging factors which may predict the need for surgery in lumbar disc herniation. Asian Spine J. 2014;8(4):446-452.

21. Fardon DF, Williams AL, Dohring EJ, Murtagh FR, Rothman SLG, Sze GK. Lumbar disc nomenclature: version 2.0: recommendations of the combined task forces of the North American Spine Society, the American Society of Spine Radiology, and the American Society of Neuroradiology. Spine J. 2014;14(11):2525-2545.

22. Sutheerayongprasert C, Paiboonsirijit S, Kuansongtham V, Anuraklekha S, Hiranyasthiti N, Neti S. Factors predicting failure of conservative treatment in lumbar-disc herniation. $J$ Med Assoc Thai. 2012;95(5):674-680.

23. Krishnan V, Rajasekaran S, Aiyer SN, Kanna R, Shetty AP. Clinical and radiological factors related to the presence of motor deficit in lumbar disc prolapse: a prospective analysis of 70 consecutive cases with neurological deficit. Eur Spine J. 2017;26(10):2642-2649.

24. Yan D, Zhang Z, Zhang Z Residual leg numbness after endoscopic discectomy treatment of lumbar disc herniation. BMC Musculoskelet Disord. 2020;21(1):273.

25. Wang Y, Gao F, Zou H. Numbness and weakness recovered at a less extent in patients with lumbar disc herniation after percutaneous endoscopic lumbar discectomy. Pain Res Manag. 2019;2019:4642701.

Disclosures and COI statement: The authors received no funding for this study and report no conflicts of interest.

Corresponding Author: Manuela D'Ercole, Department of Neurosurgery, Fondazione Policlinico Universitario "A. Gemelli," Università Cattolica del Sacro Cuore, Roma, Italy.

Published 1 June 2021

This manuscript is generously published free of charge by ISASS, the International Society for the Advancement of Spine Surgery. Copyright (c) 2021 ISASS. To see more or order reprints or permissions, see http://ijssurgery.com. 